\title{
Canibais e conflitos urbanos. Um estudo sobre uma fonte etnográfica de Maquiavel
}

\author{
Cannibals and Urban Conflicts. \\ A Study on an Ethnographic Source of Machiavelli
}

Sandro Landi

Université Bordeaux Montaigne

\section{RESUMO}

Este artigo propõe uma análise de alguns escritos de Maquiavel, à luz de um relatório manuscrito dedicado aos canibais preservado em seus arquivos familiares e dos relatos de Américo Vespúcio sobre os costumes dos Tupinambá. A hipótese desenvolvida é de que essa literatura etnográfica constitui o filtro usado por Maquiavel para interpretar os conflitos sociais na Florença do seu tempo.

\section{PALAVRAS-CHAVE}

Maquiavel; Exploraçóes geográficas; Canibais; Etnografia; Conflitos urbanos.

\section{ABSTRACT}

This paper brings together, for the first time, Machiavelli's interest in political and social conflicts and some ethnographical sources concerning the contemporary discovery of cannibals in the Caribbean as well as in Brazil (Tupinamba). The hypothesis is that knowledge of these sources represents a filter that allowed Machiavelli to reinterpret social clashes notably in Florentine urban context.

\section{KEY WORDS}

Machiavelli; Geographical Explorations; Cannibals; Ethnography; Urban Conflicts. 


\section{1. Águas e terras incógnitas}

Como foi observado recentemente, Maquiavel não escreveu sobre os chamados "grandes descobrimentos" que mudaram a concepção do mundo e sua representaçáo cartográfica. Com uma exceção, notada por Najemy: "sua única referência, indireta, às viagens, ocorre no proêmio ao primeiro livro dos Discursos sobre a primeira década de Tito Livio, quando compara os 'perigos' da tarefa de encontrar novos 'modelos e ordens' políticas aos de buscar por "mares e terras desconhecidos" (Najemy, 2009, p. I28).

O primeiro livro dos Discursos sobre a primeira década de Tito Livio abre-se com esta comparação: "Embora os homens por natureza invejosos, tenham tornado o descobrimento de novos métodos e sistemas tão perigosos quanto as descobertas de terras e mares desconhecidos, pois se inclinam por essência mais à crítica do que ao elogio” (Maquiavel, 1969, p. 17). Então, fazendo uma pausa, Maquiavel precisa seu próprio objetivo: "Tomei a decisão de seguir uma senda ainda não trilhada, movido pelo natural desejo que sempre me levou sem receios a empreendimentos que considero úteis. Se vier a encontrar dificuldades e aborrecimentos, espero colher também recompensa na aprovação dos que lançarem um olhar benevolente aos objetivos deste esforço".

Interpretar essa passagem significa, antes de mais, afrontar um paradoxo: por que razão situaria Maquiavel no início dos Discursos, cujo valor programático é inquestionável, a referência a uma experiência de exploração de terras ("a descoberta de terras e mares desconhecidos"; Cercare acque e terre incognite, Maquiavel, 2000, p. 5) que não se encontra de forma visível nas suas demais obras e, em geral, na correspondência que chegou até nós? O proêmio do primeiro livro constitui o único autógrafo conhecido dos Discursos. A análise do manuscrito mostra que Maquiavel chega progressivamente a uma formulação satisfatória ${ }^{1}$. Escreve, "Embora não seja tão perigoso discorrer de coisas novas" e se corrige duas vezes: "o descobrimento de novos métodos e sistemas" (Cercare modi et ordini nuovi, Maquiavel, I969, p. 5), e "o encontro de novos métodos e sistemas" (Trovare modi et ordini nuovi), substitui "entrar por águas e terras desconhecidas" por "a descoberta de novos mares e terras desconhecidas" e ainda por "a descoberta de terras e mares desconhecidos"; a afirmação peremptória sobre a inveja conatural ao gênero humano, (“os homens por natureza invejosos se inclinam por essência mais à crítica do que ao elogio") está deslocada, como inciso, no início da frase.

1 Pincin, 1966, p. 73-83: o borrão do proêmio está conservado na Bibiblioteca Nazionale Centrale di Firenze, Autografi Palatini, Carte Machiavelli, I, 74 (As Carte Machiavelli estão disponíveis para consulta in http://teca.bncf.firenze.sbn.it/manos/find.jsp). 
Pequenos retoques indicam, no entanto, como Maquiavel aperfeiçoa a intuição de um paralelismo entre campos diferentes e aparentemente distantes da experiência e do conhecimento: a escrita e a navegação, a política e a geografia. A comparação tornase possível através de um elemento de afinidade: o perigo que corre aquele que procura e acha coisas novas, sejam instituiçóes e métodos de governo ou regiōes ignotas, isto é, não compreendidas na representação ptolomaica do mundo. "Periculoso" tem a mesma raiz (perīe) que experimentar: a passagem indica substancialmente que quem experimenta uma visão nova das coisas - tanto na política como na geografia - se expõe necessariamente à ameaça da inveja humana. A questão da inveja como obstáculo para a realização de posiçóes e posturas individuais é vista aqui como uma constante antropológica. Todavia, sempre nos Discursos (III, 30; Maquiavel, I969, p. 407408) discorrendo sobre Savonarola, Maquiavel trata da inveja de forma mais circunstanciada: "seus sermôes contêm muitas denúncias e críticas aos 'sábios mundanos' como chamava os invejosos e todos os que se opunham a seus planos de reforma”. É quase literal a referência aos Coríntios 3.19 na pregaçáo de Savonarola: "a sabedoria do mundo é loucura diante de Deus”. A inveja de que se fala no proêmio é provavelmente da mesma natureza, Maquiavel sabe que ela o espera como autor de uma obra depositária de uma visão de mundo - como aquela que vai se definindo através dos relatórios das viagens ultramarinas - nova e paradoxal porque está em conflito com a doxa geralmente compartilhada pelas autoridades.

Maquiavel parece aludir a pelo menos dois outros autores. O primeiro é sem dúvida Ptolomeu. A expressão "terras e mares desconhecidos", parece reenviar, convencionalmente, às regióes do mundo que Ptolomeu considera como inexploradas ${ }^{2}$. O conhecimento direto ou mediado de Ptolomeu por Maquiavel é bastante provável. A Cosmografia faz parte dos livros lidos pelo seu pai, Bernardo Machiavelli ${ }^{3}$. Ademais, Ptolomeu coloca-se em um horizonte de leituras, de caráter geográfico, familiares a Bernardo e a Niccolò, entre as quais o comentário ao Somnium Scipionis de Macróbio (Maquiavel, 2007, p. 70). Última parte do De Republica de Cícero, o Somnium descreve a experiência de Cipiáo Emiliano que, no sonho, alcança um ponto de vista a partir do qual pode olhar a terra "de excelso et pleno stellarum, illustri et claro quodam loco" (Macróbio, 2003, p. 4I). Redigido ao final do século V, o comentário do Macróbio, fornece uma descrição do alto do mundo conhecido que

\footnotetext{
2 A expressão "terras e mares desconhecidos" foi retomada quase que literalmente por Francesco Guicciardini com referência à visão de Ptolomeu: "le quali Tolemeo, per confessione di tutti principe de' cosmografi, chiamava terre e mari incogniti" (Guicciardini, 1971, p. 567).

3 Machiavelli, 2007, p. I5; sobre a biblioteca de Bernardo Machiavelli, Atkinson, 2002; é necessário ter em conta que uma revisão em terceira rima e em língua vulgar da obra de Ptolomeu, obra de Francesco Berlinghieri aparece em I482 com o impressor Niccolò Tedesco: Ridolfi, I958, p. 49-62 e Dalché, 2009, p. 19-40.
} 
integra a concepçáo de Ptolomeu e menciona as terras ainda desconhecidas ("cuius situs nobis incognitus perseverat"). Que Maquiavel recorresse a Macróbio para pensar o mundo segundo uma perspectiva geográfica é uma hipótese digna de atenção.

Essencialmente, situar implicitamente a Cosmografia desde o começo dos Discursos não é um gesto neutro porque indicaria ao leitor uma comparação entre dois pontos de vista diferentes, mas convergentes no mundo: o do geógrafo e o do político. Estabelecendo um paralelo entre a Cosmografia e os Discursos, Maquiavel pretende ter um olhar do alto parecido com aquele de quem observa um mapa-múndíi ; um olhar suscetível a descrever uma nova cartografia da política. $\mathrm{O}$ proêmio dos Discursos não se limita, por conseguinte, a notar uma similitude entre a política e a geografia, mas indica ao leitor a possível interação, no plano cognitivo, entre descobrimentos geográficos e descobrimentos políticos.

\section{Maquiavel, Simone Verde e Vespúcio}

A identidade do segundo autor omitido no proêmio é mais problemática. Em seu comentário sobre essa passagem, Leo Strauss afirma que Maquiavel pretende apresentar-se como "o Colombo do mundo político e moral" (Strauss, I998, p. 28I-282). Muitos anos antes, Oreste Tommasini já havia indicado uma pista diferente e aparentemente mais crível: "cercare acque e terre incognite" alude às viagens e aos escritos de Américo Vespúcio (Tommasini, I883-I9II, p. I48-I49). Para tentar desvelar essa ausência é necessário perguntar-se quais podem ter sido os conhecimentos de Maquiavel acerca do Novo Mundo e ter em conta para esse propósito um dado até agora ignorado: a presença no arquivo residual da família Machiavelli de uma cópia manuscrita da relatório do mercador florentino Simone Verde, um dos mais antigos testemunhos das terras descobertas no Ocidente ${ }^{5}$. Como se conclui partindo do incipit do documento, Verde escreve, desde Valladolid, duas cartas a Piero Niccoli em Florença, respectivamente em março de $\mathrm{I} 493$ e em maio de I494. O copista, que declara se referir à "sustanza", é sem dúvida um contemporâneo seu. O documento encontra-se nas "Cartas Machiavelli", no envelope VI, que contêm documentos, de

\footnotetext{
4 Sobre a perspectiva possível graça à leitura de Macróbio, ver Dünne, 2009, p. I43-156.

5 Copia di certi capitoli, I494; este texto foi impresso várias vezes, a última in Italian Reports on America, 2002, p. I59-I6I; o original disponível para consulta em: http://teca.bncf.firenze.sbn.it/manos/find.jsp. Sobre a atividade mercantil de Simone Verde in Spagna ver Varela, 1988, p. 83-93.
} 
caráter público (registros, cartas de oficiais e de magistrados da República, etc.), conservados no arquivo familiar desde o começo de $1400^{6}$. A ausência das cartas autografadas de Maquiavel, explica provavelmente o desinteresse dos estudiosos por essa seção do arquivo Machiavelli. Portanto, assim como os livros pertencentes a Bernardo ou a ele emprestados, esse manuscrito - que provavelmente tem ligação com seus interesses geográficos — faz parte dos textos potencialmente lidos por Niccolò.

As cartas de Simone Verde baseiam-se no relato de três membros da frota da segunda expedição de Colombo. Como foi observado, elas se distinguem daquelas das testemunhas contemporâneas pelo ceticismo, tipicamente mercantil, com que foram levadas em conta as notícias provenientes do mundo recentemente descoberto (Symcox, 2002, p. 4). Mas tem algo a mais: Verde é também o primeiro a relatar detalhadamente informaçôes a respeito das práticas canibalescas testemunhadas em uma ilha do Caribe: "Porque acharam as pessoas que habitam aquela [ilha] bem diferentes daquelas das ilhas encontradas antes [na ilha Hispaniola] porque aqueles eram mansos e seguros, e estes sáo suspeitosos e cruéis porque comem carne humana, como se virá a entender". 7 Decepcionado pelos resultados comerciais da expedição, Verde julga que essa notícia é a única digna de ser transmitida ao seu destinatário, que, assim como ele, era provavelmente um comerciante (Jacks e Caffero, 200I, p. 78-80; 256). Trata-se ainda de um dado náo irrelevante porque, como Verde parece compreender, isso permite operar uma distinção entre os tipos humanos até esse momento descobertos por Colombo. A imagem da humanidade paradisíaca presente na carta enviada por Colombo a Gabriele Sanchez e impressa em Roma em I493, encontra-se aqui brutalmente contradita. ${ }^{8}$ Ignora-se como terá chegado o testemunho de Verde até aos Machiavelli, mas é provável que eles tenham estado entre os primeiros a conhecer esse descobrimento de caráter antropológico. Com efeito, a existência de povoaçóes antropófagas no Novo Mundo torna-se objeto de ampla circulação somente a partir do I495, quando Giuliano Dati imprime em Florença uma edição em versos da carta de Colombo, introduzindo ao final uma importante informação inédita sobre os canibais?.

\footnotetext{
6 Para uma descrição detalhada desse fundo, ver Tommasini, I883-I9II, II, I494-I500; para uma história desse fundo ver Ridolfi, 1969, p. I-23.

7 Italian Reports on America, 2002, p. I60: "perché la gente che in quella habita gli trovorono molto contraria a quelle delle isole trovorono prima perché erano mansueti e sicuri, et questi sospettosi e crudeli, perché mangiano carne humana, come intenderete".

8 Ver o texto em Marmocchi, I840, p. 409.

9 “in queste parte nulla cosa ria/ si truoua di che questi habbin paura/ saluo che c'è un'isola al'entrare/ dell'India per uoler qui ariuare./ In nella quale sta gente uillana;/da questi non mi par che siano amati/ perché dice che mangian carne humana" (Dati, I495, c. 7).
} 
Simone Verde é amigo de Colombo e, em Sevilha, faz parte da mesma companhia mercantil de Vespúcio (Varela, 1988, p. 85): a carta que este envia de Cabo Verde, em 4 de junho de I50I, a Lorenzo de Pier Francesco de Medici para contar as proezas de Cabral nas Índias orientais cita como portador e testemunha Gherardo Verde, irmão de Simone ${ }^{10}$. Nos anos seguintes, Vespúcio continua, como se sabe, a corresponder-se com protetores e amigos em sua pátria. Dentre as cartas remanescentes, duas são publicadas inicialmente em Florença, e então sucessivamente no resto da Itália e da Europa: uma (em tradução latina) para Lorenzo, conhecida como Mundus novus (1503); a outra é dirigida ao gonfaloniere Piero Soderini (Lettera delle isole nuovamente ritrovate, I505). Parece quase óbvio que Maquiavel tenha se deparado com esses materiais impressos e de larga difusão. É altamente provável que ele, na qualidade de secretário da segunda chancelaria da República, como sugeria Tommasini, tenha tido conhecimento do relatório dirigido a Soderini. Isto deve-se, por um lado, ao fato do irmáo do viajante, Antonio di Nastagio, tabeliáo do Ufficio delle Tratte, ser seu colega na chancelaria (Klein, 2013, p. 265) e, por outro lado, ao fato da longa carta que Américo envia de Lisboa ao amigo e chefe da República, recomendando-lhe Antonio, entre outras coisas, ter um caráter oficial: um tabelião, Lorenzo di Piero Coralmi, transcreve-a pela ordem da Senhoria em io de fevereiro de $1505^{11}$. Maquiavel náo pode ignorá-la ${ }^{12}$ pois tem amplo conhecimento da correspondência das duas chancelarias.

Vespúcio é quinze anos mais velho que Maquiavel e se estabelece em Sevilha, perto de uma filial do banco de Lorenzo di Pierfrancesco, em I49I. Nada prova que suas existências se cruzaram, mas mais do que um fio parece juntá-las. Estudos e descobrimentos recentes vincaram interesses e ambientes comuns. Bernardo Machiavelli e Lorenzo di Pierfrancesco compartilham o interesse por Ptolomeu e o conhecimento do cartógrafo Nicol Germano ${ }^{13}$. Os dois fazem parte do círculo do chanceler da República Bartolomeo Scala, sob cuja proteção, em I485, reúne-se um grupo de artistas, de letrados, de geógrafos, incluindo Vespúcio, que têm em comum a leitura de Lucrécio (Brown, 20I0, p. 39; Id., 1979, p. I03). Em função do progresso dos descobrimentos no Ocidente, o poeta latino, além do objeto de estudo e de

\footnotetext{
10 "[...] e per maggiore chiarezza della verità, si trovò presente Gherardo Verde, fratello di Simon Verde di Cadisi, el quale viene in mia compagnia e a voi si raccomanda" (Vespúcio, 1993, p. 82). Sobre Lorenzo di Pierfrancesco de' Medici, protetor de Vespúcio, ver Brown, I979 e 2010.

${ }^{11}$ Uma copia do século XVIII desse documento está conservada na BNCF, 2.4.509; para um estudo desse documento, Lettera a Piero Soderini, Martini (ed.), 1957.

${ }^{12}$ Sobre o controle exercido por Maquiavel sobre a correspondência das duas chancelarias, Klein, 2013, p. 265276.

13 Gentile, 1992, p. 215, que indica o empréstimo da Geographia de Ptolomeu de Niccolò Germano a Lorenzo di Pierfrancesco, do qual foi tomada nota em um registro da Biblioteca Medicea.
} 
culto para humanistas, torna-se um filtro para interpretar a humanidade desconcertante do Novo Mundo. De fato, do mesmo modo que aquela descrita no quinto livro do De rerum natura, a humanidade que resulta das primeiras testemunhas vindas de além-mar parece inscrever-se em uma fase remota e revolta da história da nossa espécie. Uma espécie de farpa afortunadamente subtraída do processo da civilização. Nessa perspectiva, não há dúvida de que o relatório de Simone Verde ajuda a fundar a alteridade antropológica do Novo Mundo, tornando possível o sucesso da descrição realística da humanidade proposta logo após por Vespúcio ${ }^{14}$. Nos anos posteriores ao I493, Ptolomeu e Lucrécio parecem portanto interagir para dar um sentido ao novo e não seria supérfluo recordar que, precisamente nesses anos e nesse mesmo ambiente, Maquiavel realizou, por motivos que ainda em parte nos escapam, a transcrição integral do poema latino ${ }^{15}$.

\section{Leituras de Vespúcio}

É verossímil que seja esse o contexto em que aconteça também a primeira recepção das cartas de Vespúcio. Conhecemos as reaçôes por elas suscitadas essencialmente graças a um fragmento de carta descoberto e publicado por Roberto Ridolfi em 1937 (Fragmento Ridolfi) (Ridolfi, 1937). Trata-se de uma resposta a uma carta de Lorenzo di Pierfrancesco, escrita provavelmente entre setembro e dezembro de 1502. Diferentemente das outras chegadas até nós, essa apresenta a particularidade de ser concebida no modelo da disputa filosófica (disputatio) e de fornecer entáo uma série de réplicas a questóes e objeçôes expressas pelos interlocutores de Vespúcio sobre os resultados dos seus descobrimentos. O documento é de grande interesse porque deixa intuir uma circulação manuscrita das suas cartas (Ibid., p. I4), e também um contexto de recepçáo e de discussão que implica vários personagens e diferentes pontos de vista. A identidade delas desvanece, mas, nos anos seguintes, cartógrafos, como Francesco Rosselli, ou exponentes da oligarquia, como Luigi Guicciardini, amigo e correspondente de Maquiavel, demostraram estarem informados sobre essas discussôes (Marzi, I900; Boorsch, 2004). O Fragmento Ridolfi testemunha, além disso, a acolhida dada por este público às informaçóes de caráter geográfico e antropológico relativas ao Novo Mundo. Vespúcio assume amiúde uma postura polêmica

\footnotetext{
${ }^{14}$ Entre eles, em particular, aquelas de Niccolo Scillacio e Michele da Cuneo, relativas à segunda viagem de Colombo, Italian Reports, Symcox e Formisano (ed.), p. I62-189. Sobre esse imaginário, as observaçóes de Neuber, 2009, p. 69-8I.

${ }^{15}$ Sobre esse descobrimento do código vaticano em que aparece o manuscrito do De natura rerum obra de Maquiavel, ver Bertelli e Gaeta, 196I, p. 545-557; sobre o contexto intelectual em que se realiza a transcriçáo ver Brown, 2010.
} 
e denuncia a incredulidade dos seus interlocutores, que ele imputa à inveja. Os pontos controversos têm a ver em particular com a posição e com o povoamento das terras descobertas ("E é certo que me encontrei tanto para o Ocidente, não desabitado mas povoadíssimo [...] e se algum invejoso ou maligno não o crê, venha a mim que com razão o declararei com autoridade e com testemunhos”. [Vespúcio, I984, p. 8o]); a ausência das riquezas nas povoaçóes indígenas ("Idem me caluniam porque eu disse que aqueles habitantes não estimam nem ouro nem outras riquezas que por nós são estimadas e tidas em grande apreço"); a origem não econômica das guerras tribais endêmicas ("porque digo que guerreiam um povo com outro e que se aprisiona, poderá parecer ao detrator que eu me contradiga, porque o guerrear e o aprisionarem-se não podem proceder se não da vontade de dominar ou da cobiça de bens temporais"16).

No proêmio dos Discursos lê-se: "Tomei a decisão de seguir uma senda ainda não trilhada, movido pelo natural desejo que sempre me levou sem receios aos empreendimentos que considero úteis". Como foi observado, Maquiavel se lembra aqui de um lugar do IV livro do De rerum natura (Najemy, 1993, p. 337). Na realidade, Maquiavel não se limita a sugerir essa referência clássica, porque "seguir uma senda" é uma metáfora trazida pela linguagem marítima ${ }^{17}$. Para dar um sentido à sua empresa ele convoca entáo Lucrécio e Vespúcio e considera os leitores dos Discursos suficientemente avisados para associar a eles seu nome. Maquiavel reivindica no proêmio um discurso novo em um mundo que tem uma matriz antiga na obra de Lucrécio e uma moderna em Vespúcio. Novo porque desviante e paradoxal, ou seja - em termos aristotélicos - em conflito com as "opinióes comuns" apoiadas pelas autoridades e portanto exposto ao risco da incredulidade e da inveja ${ }^{18}$. O proêmio parece, portanto, não somente aludir à empresa de Vespúcio, mas também conservar uma pegada da reação provocada pela leitura em comum das suas cartas, reação que é destinada, segundo Maquiavel, a se reproduzir também no caso dos Discursos.

\section{Canibais, normas, conflitos}

O proêmio dos Discursos sugere, portanto, um paralelo entre duas indagaçôes. Talvez possamos fazer um passo a mais e nos perguntar: qual o sinal que a provável

\footnotetext{
${ }^{16}$ Ridolfi, I937, p. IO-I3: "perché dicono che gueregiono l'un popolo coll'altro et che si cattivono, potrà parere al mio detrattore ch'i' mi contradicha, perché il gueregiare e 'l cativarsi non può procedere se none da voglia di dominare o da cupidigia di beni temporali”; Vespúcio, 1984, p. 83.

${ }^{17}$ Ver http://www.treccani.it/vocabolario/via2/.

${ }^{18}$ Sobre o raciocínio paradoxal cf. Aristóteles, 1990, p. 336-340 e 1995, p. 323. Sobre o estatuto da opinião comum aristotélica, ver Cassin e Baladier, 2004 e Landi, 2010.
} 
leitura de Vespúcio possa ter deixado na obra de Maquiavel? A questão, provavelmente sem resposta certa, merece de toda maneira ser posta sobretudo porque permite interrogar Vespúcio acerca da potencial mensagem política de suas leituras, ponto de vista até agora pouco estudado. Todavia, como se lê naquela carta datada de I502, Vespúcio se interessa sobretudo pelos “animais racionais" (Vespúcio, I993, p. 87). No curso das diversas exploraçôes efetuadas nas costas setentrionais do Brasil, ele afina seu olhar sobre as sociedades com as quais entra em contato às vezes durante períodos prolongados: "Trabalhei muito para estudar suas vidas, pois durante 27 dias dormi e vivi no meio deles" (Vespúcio, 1984, p. 79), afirma na mesma carta. Com uma abordagem que recorda Heródoto e sua indagação, Vespúcio não se limita a descrever instituiçóes e práticas distantes e disformes, mas procura a norma profunda e amiúde implícita ${ }^{19}$. O exemplo mais clamoroso é sem dúvida o canibalismo. Foi observado que o descobrimento da antropofagia é subversiva porque tira a confiança nas faculdades racionais do gênero humano e, consequentemente, cada distinção entre este e o mundo animal. A descriçáo proposta por Vespúcio desse fenômeno é na realidade mais complicada e as conclusóes que o leitor pode dela extrair são, sem dúvida, ainda mais radicais. De fato, segundo Vespúcio, o canibalismo não é um fenômeno natural, mas a expressão de um sofisticado ritual, ou seja, de uma racionalidade que, apesar de ser aberrante (“inrazionabile”) permite contextualizar esses grupos humanos no ambiente no qual vivem. Longe de reconduzir o canibalismo às origens ferinas dos homens, ele o considera como um dado inscrito no funcionamento dessas sociedades primordiais, ou seja, em substância, como uma potencialidade própria ao gênero humano. Amiúde, Vespúcio defronta-se com o caráter mudo ou indizível desse ou de outros costumes e logo não hesita em interrogar os indígenas: "E quis saber deles as causas das suas guerras e me responderam nada saberem salvo que nos tempos idos os seus pais assim o faziam e por recordação deles a eles deixada; nenhuma outra razão me deram e eu creio que o fazem para comerem-se um ao outro, sendo o seu comum comer carne humana, hábito comum e irracional" (Vespúcio, 1984, p. 80). Ele descobre assim um encadeamento de causas, o canibalismo é a razão profunda de guerras aparentemente sem causa; o culto aos ancestrais justifica, em última análise, as guerras canibalescas; tudo parece encontrar um sentido na natureza humana específica.

\footnotetext{
${ }^{19}$ Um exemplar manuscrito de Heródoto se encontra na biblioteca de Giorgio Antonio Vespucci, tio e tutor de Américo, agora na Biblioteca Laurenziana, Florença, Ms Plut. 70.32. Sobre a releitura de Heródoto na idade dos descobrimentos, ver Gambino Longo, 2012.
} 
Conhecemos somente de maneira fragmentária as reaçóes dos leitores de Vespúcio. Uma das mais conhecidas é aquela de um artista do círculo de Cosimo e Francesco Rosselli, Piero di Cosimo, que entre 1505 e 1507 pinta um ciclo de três mesas onde as origens cruentas da sociedade são lidas à luz de Lucrécio e de Vespúcio (Panofsky, 1937, p. I2-30; e os esclarecimentos de Ginzburg, 2003). Analogamente, quarenta anos depois, o humanista Jörg Wickram, tradutor e ilustrador das Metamorfosi de Ovídio, relê, através de Vespúcio, o mito primigênio de Licáone o antropófago, transformado por Zeus em lobo devorador de homens (Neuber, 2009, p. 78-79). Não conhecemos a metodologia utilizada por Maquiavel para ler Vespúcio, mas é provável que, como em outros casos, a antiguidade tenha constituído um filtro para interpretar os dados relativos à humanidade do Novo Mundo. Baseandose nesse extraordinário material etnográfico, questóes antigas talvez possam, ao contrário, ter encontrado respostas novas. Vespúcio permite de fato aceder a formas elementares de convivência, perceber o caráter convencional de instituiçôes políticas e religiosas, interrogar-se sobre a força dos costumes e sobre a existência de constantes na natureza humana. Nesse sentido, é possível supor que as "terras e mares desconhecidos" tenham contribuído para formular "novos métodos e sistemas": novos, justamente, porque se encontram somente no passado ou em um presente remoto, mas nunca vistos ou experimentados.

Claro que se apontam apenas algumas hipóteses sobre a leitura que Maquiavel fez de Vespúcio. Por exemplo, que esta leitura tenha contribuído para fixar a ideia do caráter conatural dos conflitos sociais. Nos Discursos (II, Io), Maquiavel discute a "opinião geral", segundo a qual o dinheiro seria a origem da guerra (Maquiavel, 1969, p. 22I-223). Trata-se de um lugar proverbial comum (pecunia nervus belli) que se tornou, como já visto aqui, o objeto de um debate como consequência das revelaçóes de Vespúcio sobre as origens não econômicas das guerras tribais. Maquiavel contesta-o igualmente: o dinheiro pode ser uma causa contingente de guerra, mas as suas razóes profundas devem, segundo ele, ser buscadas em outro lugar. Provavelmente, nas regras tácitas que fundam o funcionamento das sociedades humanas.

Tratando logo do caso específico de Florença, Maquiavel interrogará, muitos anos depois, o papel paradoxal dos conflitos na construção de uma forma duradoura de convivência ${ }^{20}$. Na História de Florença (I520-I524) Maquiavel analisa em diferentes casos o comportamento das multidóes por ocasião dos choques entre facçóes ou sublevaçóes. $\mathrm{O}$ canibalismo como êxito ritual de uma revolta surge particularmente em um episódio relativo à caçada do Duque de Atenas, ocorrida em julho de 1343

\footnotetext{
${ }^{20}$ Para uma bibliografia recente relativa às História de Florença, ver Landi, 2012.
} 
(Maquiavel, I927, p. I23; Maquiavel, 2007, p. 250). O massacre do podestá Gugliemo d'Ascesi e de seu filho de dezoito anos, que marcou a conclusão sanguinária da sublevação, é um dos lugares da memória cidadá. No seu relato Maquiavel segue a Cronica de Giovanni Villani mas acrescenta um detalhe horripilante acerca das carnes dos inimigos: "quiseram também que o gosto as saboreasse para que como todas as partes externas fossem saciadas delas, também aquelas internas ficassem saciadas delas"21. Maquiavel sobrepóe aqui à memória medieval da cidade, com seus periódicos regurgitos de violência coletiva, o imaginário relativo aos descobrimentos: gostar da carne dos inimigos é de fato uma experiência descrita por alguns indígenas a Vespúcio ("A qual dizem ser saborosíssima”) e, desde os primeiros anos de I500, graças às ediçóes ilustradas das suas cartas, torna-se um lugar comum nas representaçóes do Novo Mundo ${ }^{22}$. O detalhe não é menos relevante, porque permite anular, abruptamente, a distância entre as sociedades tribais e a sofisticada sociedade urbana cujos mecanismos foram revelados por uma crônica guerra civil: nos dois casos a guerra e o consequente devoramento dos inimigos fundam ou refundam, como nesse caso, a comunidade política.

O imaginário dos descobrimentos intervém também em uma passagem célebre do terceiro livro de História na qual um chefe da revolta dos Ciompi (1378) exorta os seus companheiros a não pararem a obra de destruição da ordem existente ${ }^{23}$. Para persuadir o seu próprio auditório, o anônimo orador recorre em dois diferentes casos a argumentos que associam as imagens em circulação sobre o Novo Mundo: à desnudez, à ausência de bens, ao canibalismo. O primeiro tem a ver com a igualdade original entre os seres humanos. Como é conhecido, o binômio nudez e igualdade é descrito com clareza por Vespúcio no Mundus Novus ${ }^{24}$ e é então interpretado no sentido político pelo ciompo: "Fiquemos todos nus e vereis que somos semelhantes e se nos vestirmos com as vestes deles e eles com as nossas vereis que sem dúvida nós pareceremos nobres e eles não nobres porque somente a pobreza e a riqueza nos

\footnotetext{
${ }^{21}$ Maquiavel, 1927, p. 123: "E perché tutti i sensi si sodisfacessero nella vendetta avendo udito prima le loro querele, veduto le loro ferite, tocco le loro carni lacere, volevono ancora che il gusto le assaporasse, acciò che, come tutte le parti di fuora ne erano sazie, quelle di dentro ancora se ne saziassero"; Villani, I823, p. 52: "ed ebbonvi di sì crudeli e con furia si bestiale e tanto animosa, che mangiarono delle loro carni crude”; Maquiavel, 2007, p. 256.

22 "Plus dico: ipsi admirantur cur nos non comedimus inimicos nostros et eorum carne non utimur in cibis, quam dicunt esse saporosissimam” (Vespúcio, 1993, p. II6). Sobre o prazer de gostar dos inimigos como lugar comum iconográfico ver Neuber, 2009, p. 72.

${ }^{23}$ Maquiavel, 1927, p. I57. Sobre esse passo existe uma ampla literatura, Landi, 20I2, p. I52-156.

24 "Omnes utriusque sexus incededunt nudi, nullam corporis partem operientes" [...] "Non habent pannos neque laneos neque lineos neque bombicinos, quia nec eis indigent nec habent bona propria, sed omnia communia sunt” (Vespúcio, I993, p. II2-II4).
} 
desigualam"25. O segundo está relacionado com o fim dos conflitos, que encontram pretexto na cupidez de alguns e na indigência de outros, mas que não podem conhecer outro resultado que a aniquilaçáo, mediante assimilação, do adversário: "os homens se devoram uns aos outros e sempre se sai mal quem menos pode"26, afirma o orador recorrendo neste caso a uma verdadeira e própria sentença visual (Neuber, 2009, p. 72).

Muitos anos decorreram desde que as primeiras notícias sobre antropofagia dos povos do Novo Mundo penetraram no mundo culto florentino. Com o tempo, a leitura e a discussão das testemunhas produziu-se uma nova leitura do mundo: desde o canibalismo como simples fenômeno tribal, à constante antropológica, à metáfora, enfim, das relações políticas e sociais.

\section{Bibliografia}

Aristóteles. (1990). Organon, V, Les topiques (VIII, 5). Paris: Vrin.

Aristóteles. (1995). Les réfutations sophistiques. Paris: Vrin.

Atkinson, C. (2002). Debts, Dowries, Donkeys. The Diary of Niccolo Machiavelli's Father, Messer Bernardo, in Quattrocento Florence. Frankfurt a. M.: Peter Lang.

Bertelli, S. e Gaeta, F. (196I). "Noterelle machiavelliane. Un codice di Lucrezio e di Terenzio", Rivista Storica Italiana, 73, pp. 545-557.

Boorsch, S. (2004). "The Case for Francesco Rosselli as the Engraver of Berlinghieri's Geographia", Imago Mundi, 56, pp. I52-I69.

Brown, A. (1979). "Pierfrancesco de' Medici, I430-I476: A Radical Alternative to Elder Medicean Supremacy?", Journal of the Warburg and Courtauld Institutes, 42, pp. 8I-IO3.

Brown, A. (2010). The Return of Lucretius to Renaissance Florence. Cambridge (Mass.) and Londres: Harvard University Press.

Cassin, B. e Baladier, C. (2004). "Doxa”, em B. Cassin (org.), Vocabulaire européen des philosophies. B. Cassin (ed.). Paris: Seuil-Robert.

Copia di certi capitoli d'una lettera iscritta per Simone Verde, dal Borgo a San Lorenzo di Mugello, il quale al presente si truova in Vagliadoli di Castiglia e iscrive di quivi a Piero Niccoli in Firenze per lettere de di 20 di marzo 1493 e dipoi per un'altra lettera de di io di maggio I494, em Biblioteca Nazionale Centrale Firenze (BNCF), Autografi Palatini, Carte Machiavelli, VI, I4.

\footnotetext{
25 "Spogliateci tutti ignudi: voi ci vedrete simili, rivestite noi delle veste loro ed eglino delle nostre: noi senza dubio nobili ed eglino ignobili parranno; perché solo la povertà e le ricchezze ci disaguagliano" (Maquiavel, 2007, p. 186).

26 "Gli uomini mangiono l'uno l'altro, e vanne sempre col peggio chi può meno" (Maquiavel, 2007, p. I87).
} 
Dalché, P. G. (2009). "Pour une histoire des rapports entre contemplation et cartographie au Moyen Âge”. In: Les méditations cosmographiques à la Renaissance. Paris: PUPS, 19-40.

Dati, G. (I495). La lettera dell'isole che ha trovato nuovamente el re di Spagna, Firenze, [s.n.].

Dünne, J. (2009). "Méditation, médialité, subjectivité: du regard "d'en haut” au panoptisme cartographique". In: Les méditations cosmographiques à la Renaissance. Paris: PUPS, 19-40.

Gambino Longo, S. (org.) (2012). Hérodote à la Renaissance, Turnhout: Brepols.

Gentile, S. (1992). Firenze e la scoperta dell'America. Umanesimo e geografia nel '400 fiorentino. Florença: Olschki.

Ginzburg, C. (2003). "Mémoire et distance. Autour d'une coupe d'argent doré (Anvers, ca. 1530)", Diogène, I, 20I, pp. I08-I25.

Guicciardini, F. (197I). Storia d'Italia, VI, 9. S. Seidel Menchi (ed.). Turim: Einaudi.

Jacks, P. e Caferro, W. (200I). The Spinelli of Florence: Fortunes of a Renaissance Merchant Family, University Park: Pennsylvania State University Press.

Klein, F. (20I3). Scritture e governo dello stato a Firenze nel Rinascimento. Cancellieri, ufficiali, archivi. Florença: Edifir.

Landi, S. (20I0). "Opinion publique”. In : O. Christin, Dictionnaire des concepts nomades en sciences humaines. O. Christin (ed.). Paris: Métailié.

Landi, S. (2012). “Fama', Humors, and Conflicts. A Re-reading of Machiavelli's Florentine Histories". In: M. Rospocher (org.), Beyond the Public Sphere Opinions, Publics, Spaces in Early Modern Europe, Bolonha-Berlim: Il Mulino-Duncker \& Humblot, pp. I37-I64.

Machiavelli, B. (2007). Libro di Ricordi. C. Olschki (ed.), prefácio de Leandro Perini. Roma: Edizioni di storia e letteratura.

Macrobe. (2003). Commentaire au songe de Scipion, Tome II, livre II. Paris: Les Belles Lettres.

Maquiavel, N. (1927). Istorie fiorentine, I. Florença: Sansoni.

Maquiavel, N. (2000). Discorsi sopra la prima deca di Tito Livio. Turim: Einaudi.

Maquiavel, N. (1969). Comentários sobre a primeira década de Tito Livio. Traduzido por S. Bath. Brasília: Editora da Universidade de Brasília.

Maquiavel, N. (2007). História da Florença. Sáo Paulo: Martins Fontes.

Marmocchi, F. C. (1840). Raccolta di viaggi dalla scoperta del nuovo continente fino a'di nostri, I. Prato, Giachetti.

Martini, G. S. (ed.) (1957). Lettera a Piero Soderini: Lisbona, sett. I504, secondo il cod. 2. 4. 509 da Biblioteca Nazionale di Firenze. Florença: Olschki. 
Marzi, D. (1900). Notizie intorno ad un mappamondo e ad un globo terrestre posseduto nel 1509 da Luigi Guicciardini. Florença: Ricci.

Muir, E. (1984). "The Cannibals of Renaissance Italy”, Syracuse Scholar, 5, 5-I4.

Najemy, J. M. (1993). Between Friends. Discourses of Power and Desire in the Machiavelli-Vettori Letters of I513-I5I5. Princeton: Princeton University Press,.

Najemy, J. M. (2009). Machiavelli Between East and West, em From Florence to the Mediterranean and Beyond. In: D. Ramada Curto, E. R Dursteler, J. Kirshner, F. Trivellato (orgs.), Essays in Honour of Anthony Molho. Florença, Olshski, pp. 27-I45.

Neuber, W. (2009). "Mnemonic Imagery in the Early Modern Period: Visibility and Collective Memory". In: D. Beecher e G. Williams (orgs.), Ars reminiscendi. Mind and Memory in Renaissance Culture. Toronto: CRRS, pp. 69-8I.

Panofsky, E. (1937). "The Early History of Man in a Cycle of Paintings by Piero di Cosimo", Journal of the Warburg Institute, I, pp. I2-30.

Pincin, C. (1966) "La prefazione e la dedicatoria dei Discorsi di Machiavelli", Giornale storico della Letteratura italiana, I43 (I), pp. 73-83.

Ridolfi, R. (1937) "Una lettera inedita di Amerigo Vespucci sopra il suo terzo viaggio", Archivio storico italiano, 95, pp. 3-20.

Ridolfi, R. (1958). La stampa in Firenze nel secolo XV. Florença: L.S. Olschki.

Ridolfi, R. (1969). "Le carte del Machiavelli”, La Bibliofilia, 7I, I, I-23.

Strauss, L. (1998). Gerusalemme e Atene. Studi sul pensiero politico dell'Occidente. Turim: Einaudi.

Symcox, G. (2002). Historical Introduction. In: Italian Reports on America, I493-I522. Accounts by Contemporary Observers. G. Symcox e L. Formisano (ed.). Turnhout: Brepols.

Symcox, G.; Formisano. L. (ed.). (2002) Italian Reports on America, I493-I522. Accounts by Contemporary Observers. Turnhout: Brepols.

Tommasini, O. (I883-I9II). La vita e gli scritti di Niccolò Machiavelli nella loro relazione col machiavellismo. Storia ed esame critico, I e II. Roma-Turim-Florença: Loescher.

Varela, C. (1988). Colón y Los Florentinos. Madri: Alianza.

Vespúcio, A. (1984). Novo mundo. Cartas de viagens e descobertas. Traduzido por Luiz Renato Martins, Porto Alegre.

Vespúcio, A. (1993). Il Mondo Nuovo di Amerigo Vespúcio. M. Pozzi (ed.). Turim: Edizioni dell'orso.

Villani, G. (I823). Cronica, VII. Florença, Magheri. 